\title{
Yasuko Eshima, Le Christ fin de siècle
}

\section{Mario Richter}

\section{(2) OpenEdition}

\section{Journals}

\section{Edizione digitale}

URL: http://journals.openedition.org/studifrancesi/35061

DOI: 10.4000/studifrancesi.35061

ISSN: 2427-5856

\section{Editore}

Rosenberg \& Sellier

\section{Edizione cartacea}

Data di pubblicazione: 1 novembre 2005

Paginazione: 444

ISSN: 0039-2944

\section{Notizia bibliografica digitale}

Mario Richter, «Yasuko Eshima, Le Christ fin de siècle», Studi Francesi [Online], 146 (XLIX | II) | 2005,

online dal 30 novembre 2015, consultato il 19 avril 2021. URL: http://journals.openedition.org/ studifrancesi/35061; DOI: https://doi.org/10.4000/studifrancesi.35061

\section{Questo documento è stato generato automaticamente il 19 avril 2021.}

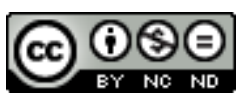

Studi Francesi è distribuita con Licenza Creative Commons Attribuzione - Non commerciale - Non opere derivate 4.0 Internazionale. 


\title{
Yasuko Eshima, Le Christ fin de siècle
}

\author{
Mario Richter
}

\section{NOTIZIA}

YASUKo ESHIMA, Le Christ fin de siècle, Du Lérot, Tusson, Charante, 2002, pp. 263.

1 Mettere a fuoco l'evoluzione della figura di Cristo in un secolo complesso come l'Ottocento non è impresa di poca difficoltà. Y. Eshima ha affrontato l'argomento con indubbia dottrina e ordine intellettuale. Allo scopo di far risaltare con più efficace evidenza la specificità di Cristo nell'immaginario fin de siècle, lo studioso ha opportunamente dedicato la prima parte del suo libro a una illustrazione del Cristo romantico, soffermandosi soprattutto su Ernest Renan e la sua Vie de Jésus (ricerca della vita interiore, della religione vissuta in spirito e verità), su Jules Michelet (ricerca della Giustizia), su George Sand (ricerca dell'energia divina della Rivoluzione) e su Victor Hugo, specie quello dei Misérables (ricerca del progresso spirituale e del riscatto del Male). Per tutto ciò si è naturalmente avvalso dello studio di Frank P. Bowman, Le Christ romantique (Genève, Droz, 1973). Il Cristo romantico ha un carattere unificante, globalizzante. È un Cristo che si definisce in una forma di ottimismo umanistico.

Nella seconda parte è in primo luogo studiato il Cristo che Ernest Hello e poi Léon Bloy hanno osservato e vissuto con forza nell'ottica della povertà.

La terza parte mette in luce la funzione mediatrice dell'arte per consentire l'accesso a una esperienza propriamente spirituale di Cristo nel suo aspetto doloroso. Huysmans vi occupa un posto di primo piano e trova una illuminante illustrazione nelle pagine che gli dedica Y. Eshima. Anche Verlaine ottiene una suggestiva collocazione in questo contesto fin de siècle, essendo visto dallo studioso nella luce unificante di una «mystique de la sensation» attiva già dai Poèmes saturniens.

Guidata dall' aspirazione romantica verso l'infinito, la fin de siècle si rivela segnata dalla imperiosa mediazione baudelairiana. Rifiuta infatti l'ideologia del progresso e l'ottimismo filosofico a cui diedero ascolto Michelet, Sand, Renan e Hugo. Pur caratterizzata dal soggettivismo e dalla frantumazione, la fin de siècle mette soprattutto 
l'accento sulla sofferenza di Cristo esaltata da un'arte che si sofferma quasi morbosamente sull'incarnazione, sulla presenza del corpo sottoposto alle torture.

5 Il libro è corredato da istruttive illustrazioni e completato da un utile bibliografia. 